\title{
Toque da Ciência: bases para um estudo de acompanhamento
}

\author{
Juliano Maurício de Carvalho* \\ Aline Emi Naoe** \\ Érica Masiero Nering*** \\ Fábio de Lima Alvarez ${ }^{* * * *}$ \\ João Guilherme D'Arcadia****** \\ Mateus Yuri Passos******
}

Resumo: Este artigo reflete sobre as bases para estudos de acompanhamento do programa Toque da Ciência, produto jornalístico de divulgação científica, desenvolvido na Unesp. Em caráter de iniciação científica, são desenvolvidas pesquisas de avaliação crítica do programa, por meio de estudos de apropriação técnica, recepção, e análise do discurso.

Palavras-chave: Divulgação científica. Análise do discurso. Apropriação técnica. Estudos de recepção. Estudo de acompanhamento.

Resumen: Este artículo reflecte sobre las bases para estudios de acompañamiento del programa Toque de la Ciencia, producto periodístico de popularización de la ciencia desarrollado en la Unesp. En carácter de iniciación científica, realizase una evaluación crítica del programa por medio de investigaciones sobre apropiación técnica, recepción y discurso.

Palabras clave: Popularización de la ciencia. Análisis del discurso. Apropiación técnica. Estudios de recepción. Estudios de acompañamiento.

Abstract: This paper discuss the bases for monitoring studies on A Science Touch, a science popularization product developed at Unesp. There are science initiationlevel researches for critical evaluation of the program, sorted in technical appropriation and reception studies and discourse analysis.

Keywords: Science popularization. Discourse analysis. Technical appropriation. Reception studies. Accompaniment studies. 


\section{Introdução}

O Toque da Ciência é um produto jornalismo em áudio, a ser veiculado na internet e em rádio, e tem como objetivo divulgar a ciência para um público leigo por meio de uma linguagem direta e acessível e um meio de comunicação popular e barato (o rádio) e, desse modo, dar visibilidade à produção científica e aproximar a sociedade dessa realidade de modo contextualizado e crítico, permitindo a compreensão do que é pesquisado e de que maneira isso é feito. $\mathrm{O}$ projeto é, atualmente, financiado pelo $\mathrm{CNPq}$ e pela pró-reitoria de extensão da Unesp.

À práxis jornalística, contudo, deve somar-se uma reflexão teórica. Uma vez que o programa Toque da Ciência se propõe como uma alternativa inovadora para a divulgação da ciência e o estabelecimento de uma cultura científica (cf. VOGT, 2006), o produto deve ser estudado em seus diversos aspectos (técnica, discurso, recepção), de modo a verificar se programa atinge seus objetivos.

Assim, os participantes realizam uma pesquisa paralela que permite, por um lado, acompanhar de modo científico a produção de programa de divulgação científica e sua repercussão. Por outro, proporciona aos realizadores uma visão crítica sobre o programa, ainda em seu primeiro ano de existência e um mapa da produção e crítica de divulgação científica, uma vez que os levantamentos bibliográficos envolverão também estudos de caso relacionados a apropriação técnica, discurso e recepção. Assim, pontos positivos poderão ser aprimorados e pontos falhos revistos e corrigidos, para que haja uma divulgação da ciência mais eficaz e de melhor qualidade.

\section{Desafios para falar de ciência}

A divulgação científica tem como objetivo aumentar o conhecimento do público em geral a respeito daquilo que a pesquisa científica produz - um de seus braços é o jornalismo científico, ou seja, a divulgação realizada em notícias, reportagens, artigos, crônicas e outras modalidades jornalísticas. Há vários nomes indicados para o mesmo processo (popularização da ciência, vulgarização da ciência). Carlos Vogt (2006) propõe o termo cultura científica para abrigar as diversas modalidades de levar a ciência ao público leigo, por meio de meios de comunicação, museus, centros de 
ciência, jogos educativos etc. É fundamental que a população seja informada a respeito do que é produzido em ciência, tanto pelo direito inalienável ao conhecimento (cf. PINSKY, 2003), sem o qual se corre o risco de ficar à margem dos debates sobre assuntos de relevo, quanto pelo fato de a maior parte das pesquisas ocorrer em instituições públicas, financiada com verba oriunda do pagamento de impostos.

É importante para a ciência ser conhecida e compreendida pelas pessoas. Essa compreensão, o benefício que a pesquisa traz, os horizontes humanos que amplia, as perspectivas que abre à fantasia e à esperança são garantias de suporte político num momento em que o mundo da ciência enfrenta os mais intensos conflitos da era contemporânea. (LAGE, 2003, p.12)

A tradição de comunicação sobre pesquisas científicas teve início no século XVI (cf. BURKETT, 1990, p.27), na cidade italiana de Nápoles, onde pesquisadores se reuniam para divulgar entre si resultados parciais e finais de suas atividades de pesquisa. Em 1665, o inglês Henry Oldenburg lançou Philosophical Transactions, primeira publicação de jornalismo científico. Segundo Burkett (1990, p. 28), “Oldenburg estabeleceu precedentes de cientistas funcionando como editores de periódicos na sociedade científica e para publicações em vernáculo. Esses conceitos fortaleceram a pesquisa científica na Europa”. No século XIX, muito do que se produzia em jornalismo científico se referia a expedições exploratórias, características daquele momento, especialmente por conta do neocolonialismo inglês. Atualmente, principalmente no Brasil, tanto cientistas como jornalistas praticam a divulgação científica nos meios de comunicação. ${ }^{1}$

Um dos maiores desafios da divulgação científica é o uso da linguagem, especialmente em relação ao jargão dos pesquisadores. No início da década de 1970, a expansão de alcance da televisão nos Estados Unidos levou a uma crise dos jornais, cujo texto era considerado difícil. O interesse em recuperar os leitores perdidos mobilizou editores a encomendarem uma pesquisa de opinião para compreender o novo contexto vivido pelos leitores e as reformas necessárias a se implementar nos veículos impressos. $\mathrm{O}$ relatório de Ruth Clark, vice-presidente de mídia da companhia Yankelovich, Skelley \& White indicou a urgência de uma reforma nas publicações, utilizando uma linguagem mais didática e ilustrativa, utilizando recursos visuais como boxes e os atuais infográficos (SAVIANI REY, 2000-2001). 
O principal produto concebido a partir das constatações do Relatório Ruth Clark foi o jornal USA Today. No Brasil, a Folha de S. Paulo foi o primeiro veículo a adotar a mudança, na década de 1980.

Porém, mesmo com o uso dessas estratégias, o grande público não tem conhecimento sobre muito do que a ciência produz atualmente.

Os avanços já conseguidos pela ciência no Brasil ainda não são suficientemente conhecidos, a não ser em círculos restritos. Apesar do enorme interesse por C\&T [Ciência \& Tecnologia], os dados referentes à percepção da influência da ciência indicam que os resultados do avanço científico e tecnológico estão distantes da vida diária das pessoas [...] Os governos em todos os níveis e os pesquisadores de um modo geral têm o dever de prestar contas à sociedade sobre as realizações na área, contribuindo para a evolução educacional e cultural da população. (OLIVEIRA, 2002, p.12-14).

Em certos casos, como identificado por BELDA (2002), há uma má divulgação científica, resultante principalmente da confusão de conceitos. $\mathrm{O}$ pesquisador identificou, na cobertura jornalística sobre organismos transgênicos, que estes eram confundidos com mutantes e híbridos, além de passarem por uma avaliação qualitativa que oscilava entre progresso e precaução.

A linguagem científica utiliza um vocabulário excessivamente técnico e específico (BELDA, 2002), do qual não poucos pesquisadores relutam em abrir mão. Uma das dificuldades na divulgação da ciência consiste na compreensão de que o papel do jornalista é o de um mero tradutor (cf. BURKETT, 1990, p. 8-9) do jargão científico para a linguagem comum. Baseada numa cautela com viés para o didatismo que subestima a capacidade de compreensão do receptor, muitas vezes a tentativa de explicar a ciência de forma lúdica chega a ponto de distorcer o discurso científico e criar um atrito entre cientistas e repórteres, estes por considerarem os cientistas muito rigorosos quanto aos dados a ser divulgados, aqueles por considerarem os jornalistas muito superficiais e displicentes (cf. LAGE, 2001, p.123).

É preciso um meio termo entre a restrição e o ruído, uma forma de promover a reformulação discursiva com um rigor tal que se evite a falsificação dos conceitos referenciais. De um ponto de vista teórico que considere a noção de obstáculo lingüístico, é preciso, então, fazer com que se revelem as 
relações de aproximação e distanciamento semântico mantidas entre as redes de significação desses diferentes universos lingüísticos, o que talvez levaria o pesquisador, diante de um corpus específico, a conhecer até que ponto o discurso jornalístico mantém rigor conceitual sobre seus referentes científicos. (BELDA, 2002, p. 126).

Graça Caldas (2004) compreende que o papel de tradutor é limitado, cabendo ao jornalismo, enquanto, espaço de mediação pública, retratar a produção da ciência por uma perspectiva crítica. É preciso que o cidadão não apenas tenha conhecimento sobre o que a pesquisa científica produz, mas também seja capaz de apresentar um raciocínio crítico sobre essa produção. É preciso haver "inquietação e preocupação" com o desenvolvimento da ciência, pois "somente o debate público e uma educação científica podem evitar equívocos e mal entendidos” (SILVA, 2003a, p.58).

$O$ poder da divulgação científica não deve ser subestimado. Para Thomas e Durant (apud SABBATINI, 2006) os benefícios da divulgação científica são também benefícios à ciência, uma vez que a difusão do conhecimento permite maior captação de recursos. Também são beneficiadas as economias nacionais e a sociedade como um todo, além de haver progressos intelectuais, estéticos e morais, pois a ciência é parte da cultura.

A última assertiva se constitui em todo o problema da divulgação científica para o ensaísta e crítico de ciências Jean-Marc Lévy-Leblond (2006) - para ele, a ciência afastou-se da cultura, pela natureza de seus procedimentos, e o público não conhece ou se interessa por ela por não ter meios de influir nos rumos da pesquisa científica. A afirmativa remete diretamente à exclusão de grande parte da população da esfera pública de debates, assumida pelos meios de comunicação. É preciso, portanto, haver uma reinserção da ciência na cultura - e, se o jornalismo não é suficiente para tanto, ao menos tem capacidade para ajudar no processo. Assim, é mister que seja alta a qualidade do tratamento da informação veiculada.

Fabíola Oliveira (2002, p.43) afirma que a redação no jornalismo científico deve ser "coloquial, amena, atraente, objetiva e simples", características que condizem perfeitamente com a dos textos para rádio e televisão. Há possibilidade de se explorar temas complexos e densos com amenidade na explicação de conceitos - acompanhando, inclusive, a percepção crítica dos próprios cientistas a respeito de assuntos abordados, evitando problemas como o identificado por Marcelo Leite (2003, p.1) na divulgação de pesquisas relacionadas ao Projeto Genoma. Segundo o jornalista, "tanto a 
divulgação do seqüenciamento do genoma quanto sua cobertura pela imprensa foram marcadas por uma atmosfera de determinismo genético que já não correspondia à própria realidade da pesquisa genômica”.

\section{Apropriação técnica: inovadora?}

A internet vem se afirmando, cada vez mais, como uma plataforma multimídia, ou seja, que comporta diversos tipos de linguagens midiáticas. Essas linguagens encontram na web novas funções e possibilidades, que muitas vezes diferem de sua utilização pensada anteriormente.

A pesquisa tratará principalmente, do meio sonoro utilizado na rede, fazendo uma reflexão crítica acerca do Projeto Toque da Ciência, buscando analisar se a forma como este vem se apropriando das novas tecnologias disponíveis na web para produzir material jornalístico de divulgação científica é de fato inovadora, diferencial.

Nélia Del Bianco (2001) reconhece a internet como um meio hipertextual, que possibilita a integração das diversas linguagens midiáticas, capazes de interagir entre si e se complementarem, possibilitado assim uma cobertura jornalística mais plural. Del Bianco, no entanto, ressalta: "nem sempre essa junção de diferentes linguagens acontece na perspectiva da integração. É mais comum do que se imagina ver o domínio da lógica da separação dessas linguagens em canais" (2001, p.1). Vale ressaltar que a autora aborda o jornalismo de maneira geral, não tratando especificamente do jornalismo científico.

Posto isso, partimos agora para a reflexão acerca do projeto Toque da Ciência. O Projeto se propõe a produzir drops em formato fonográfico, pequenos programas de um minuto e meio, a serem disponibilizados na internet para qualquer rádio, tanto hertziana quanto on-line, interessadas em veicular o conteúdo produzido. Além disso, também produzirá pequenos programas em formato áudio-visual, também de um minuto e meio, a serem disponibilizados para $\mathrm{TV}$ s on-line ou convencionais que os queiram transmitir.

Como esta é uma reflexão hipotética, visto que o site do projeto ainda se encontra em construção, e que a produção dos vídeos ainda não foi iniciada, trataremos de um modelo de site ideal.

Del Bianco (2001) apresenta a teoria do hipertexto, desenvolvida por George P. Landow, que trata da integração do áudio com as demais 
linguagens da web. Alguns aspectos abordados por Landow, e que são pertinentes à nossa discussão, se referem à interatividade e ao tamanho dos arquivos de áudio. $\mathrm{O}$ site deve possibilitar um canal de retorno adequado, que permita aos usuários postarem seus comentários acerca do material produzido. Em relação ao tamanho dos arquivos, estes devem ser compactos o suficiente para serem baixados de maneira rápida. Outros pontos abordados nesta teoria são a multiniliearidade, a intertextualidade e a intratextualidade. Multiniliearidade: enquanto o áudio é ouvido, o usuário deverá ter mobilidade e autonomia para navegar livremente pelo site. Intertextualidade: o áudio deve complementar a informação do texto (no nosso caso é o contrário, visto que a informação principal é a em formato de áudio). Intertextualidade: o material audiofônico deve nos remeter a outros arquivos sonoros.

O site do projeto deverá disponibilizar, assim como afirma a teoria de Landow (apud Del Bianco, 2001), “drops” fonográficos compactos para download, possibilitando sua rápida execução pelos usuários. Outro ponto passível de utilização é a transmissão do áudio por "streaming", ou seja, um fluxo contínuo de dados, que permite ao usuário, ao acessar o arquivo de áudio, ouvi-lo à medida em que o download é realizado. É o caso das web rádios e web $\mathrm{TV}$.

Em relação aos outros aspectos abordados por Landow, o site deve ser pensado e elaborado sempre visando a integração entre o seu material disponibilizado, permitindo complementaridade de informações através de todos os formatos midiáticos disponíveis no site. Por exemplo, ao baixar um drops em formato radiofônico, o usuário deverá ser capaz de obter, na forma de texto, além da transcrição do que foi dito, acesso a mais informações referentes ao assunto, que abordem outros pontos relativos à pesquisa divulgada que, por algum motivo, não estão presentes em formato sonoro.

O site também deverá ter um layout claro, facilitando a navegação do usuário, possibilitando-o entender rapidamente como a informação que procura pode ser obtida. Outro aspecto importante que deverá ser tratado é a questão do canal de retorno. Esta ferramenta deverá possibilitar aos usuários entrar em contato com os membros do projeto, permitindo que aqueles possam enviar suas críticas e sugestões, permitindo um melhor desenvolvimento do Projeto. Podem ser criados fóruns on-line de discussão, disponibilizados e-mail de contato, telefone, e, até mesmo programas que permitem a comunicação instantânea, tanto escrita quanto falada (messengers).

Portanto, o Toque da Ciência deverá, além de disponibilizar os 
conteúdos padrões produzidos, dar conta de permitir mobilidade adequada aos seus usuários e informações complementares que tornem a navegação no site mais atraente e produtiva, tornando-o capaz de atrair cada vez mais pessoas e, dessa forma, melhor atingir o seu objetivo, que é o de divulgar a ciência.

\section{Ciência e discurso}

A produção textual do Toque da Ciência também pode passar por uma análise de discursos, uma vez que, no processo de sua elaboração, não há isenção de intenções. Desde o momento que o estudante entra em contato com o pesquisador, até a elaboração do programa radiofônico é elaborado, podemos avaliar criticamente cada passo, sob um olhar proposto pela Análise de discurso. Serão levadas em conta as condições sociais de produção, ou seja, incluiremos todo o contexto de interação comunicacional (a produção, circulação e consumo).

No primeiro momento, há o contato do jornalista com o pesquisador (LAGE, 2001). A aceitação do convite já indica um interesse deste em divulgar os resultados de sua pesquisa e torná-la conhecida. Seu interesse não está isento de intenções; pelo contrário: almeja-se desde um reconhecimento do trabalho, que geralmente fica limitado às universidades, até um possível prestígio.

Passamos para a entrevista, que é a forma do divulgador tomar conhecimento sobre dados da pesquisa sobre a qual irá produzir um texto. Com as informações assim obtidas, começa a etapa de produção textual da lauda radiofônica que será lida pelo próprio pesquisador. É aí que começa o que a Análise de discurso chamaria de análise de conteúdo (PINTO, 1999).

A análise de conteúdo é uma das formas que os analistas encontraram para interpretar um discurso. Seu método básico é a normatização, na qual se utiliza a transcrição do conteúdo de textos orais na tentativa de torná-los mais fáceis de analisar e comparar a outras produções. O grande problema disso é que, ao transcrever o texto, perde-se a superfície intencional do discurso inicial.

Ao levarmos essa teoria para o Toque da Ciência, chegamos à conclusão de que, ao produzir o texto lido pelo pesquisador, o jornalista impregna sua produção de suas próprias intenções. Assim, as intenções iniciais do pesquisador acabam se camuflando atrás da ótica do divulgador 
científico.

O estudante seria o que a Análise de discurso chamaria de autor empírico (cf. PINTO, 1999) do texto, enquanto o pesquisador seria seu emissor/locutor. Geralmente, o autor empírico de um texto é também o seu enunciador, uma vez que podemos identificá-lo pelo pronome "eu". Mas o Toque da Ciência é um exemplo de que nem sempre isso acontece, sendo mais uma preocupação dos analistas de discurso, uma vez que o sujeito do discurso é essencial para que se faça uma análise além da superfície textual, para um contexto mais completo.

Não se pode esquecer que, muito mais do que refletir as intenções de um ser isolado, o discurso reflete as intenções de um indivíduo dentro de um determinado contexto sócio-histórico, como uma produção/reprodução de sentidos sociais e ideológicos. Ao analista de discursos, segundo Milton José Pinto (1999), cabe procurar vestígios que permitam não só interpretar o texto em seu contexto situacional imediato, como também em seu contexto institucional e em seu contexto sociocultural.

Os traços encontrados na produção textual para o Toque da $\mathrm{Ci}^{-}$ ência nos remetem em um primeiro momento, à situação (um divulgador científico procura pesquisadores interessados em falar sobre sua pesquisa). Já em um segundo momento, analisamos o seu contexto institucional (um estudante de jornalismo faz um trabalho para divulgação científica de pesquisadores doutorados). Em um contexto sociocultural amplo, um projeto de divulgação científica via rádio (meio mais acessível) busca uma minoria social de doutores, dispostos a dividir com a maioria da população sua pesquisa que, por sua vez, foi bancada por verba oriunda dos impostos (pagos pela grande massa).

$\mathrm{O}$ analista de discursos preocupa-se menos com o que está escrito do que com o como e o porquê do texto. A ele interessam os modos de dizer, que podem usar determinada linguagem ou semiótica, pode se relacionar com o interlocutor de diversas maneiras e pode seduzir seu receptor por meio da escolha de palavras ou ambientação do discurso.

No Toque da Ciência, a linguagem é um misto do que prega a maneira jornalística de escrever (objetividade, clareza) com a linguagem científica (mais densa). Contudo, a diferença do estilo de divulgação científica adotado pelo Toque da Ciência é a formulação de um produto radiofônico. Isso muda completamente a forma de interagir a ciência com o público em geral. $\mathrm{O}$ fato de o próprio pesquisador falar ao ouvinte já é uma forma de aproximar o público ao conteúdo que lhe será passado, de romper a barreira que há entre as pessoas e o discurso científico. 
Voltando à problemática de sujeito enunciador, colocamos em cena mais um aspecto a ser pensado ao se fazer a Análise de discurso, que envolve a elaboração dos discursos como um todo: não há discurso original. Todo discurso é elaborado através das interpretações e absorção dos conteúdos por parte do emissor, que virá a ser o enunciador (PINTO, 1999). $\mathrm{O}$ pesquisador faz apenas a reprodução de discursos com os quais teve contato em sua vida ou durante a elaboração de sua pesquisa. Mesmo que seu assunto seja inovador ou baseie-se em resultados empíricos, o ponto de partida se deu pelo discurso de outra pessoa, que por sua vez reproduziu o discurso de outrem.

Logo, é muito difícil para o analista identificar a intenção verdadeira de determinado discurso. Partimos, portanto, para as superfícies textuais encontradas pelo analista, que vão ajudá-lo a chegar mais próximo a uma interpretação. As marcas ou pistas encontradas no discurso não estarão sujeitas à apenas uma interpretação. A intenção subjetiva de produção de um discurso pode ser apenas uma, mas nem sempre é aquela encontrada pelo analista. Geralmente, o sentido analisado acaba sendo mais amplo, uma vez que um único discurso dá brechas para sentidos diversos.

O produto do Toque da Ciência, por todos os motivos aqui apresentados pelo viés da Análise de discurso, rompe mais uma vez com o mito da objetividade jornalística. O processo de produção textual da divulgação científica, assim como todas as outras, está sujeito a diversas interpretações e influências dos produtores do discurso apresentado ao ouvinte que, por sua vez, também elabora juízos interpretativos. Assim, a análise de discurso dos programas realizados permitirá avaliar se o discurso sobre a ciência é adequado à proposta do projeto, e como são reproduzidos os valores científicos.

\section{Recepção: repercussão do projeto entre jornalistas, pesquisa- dores e leigos}

Para ocorrer, a comunicação exige três elementos básicos: emissor, mensagem e receptor. É um processo aparentemente simples, mas que envolve uma série de fatores importantes que podem afetar os dois eixos da comunicação e a própria mensagem. Por ser o alvo de toda comunicação e o ponto inicial do processo de resposta, o receptor representa um elemento de destaque, essencial para avaliar a eficácia da comunicação. Assim, o 
processo de recepção dos meios de comunicação receberá especial atenção neste trabalho.

A divulgação científica é um tipo especial de comunicação, já que tem uma preocupação ainda maior com a compreensão do conteúdo da mensagem. Mesmo com os avanços na área da Ciência e Tecnologia nas últimas décadas, a informação científica é até hoje conhecida por ser de difícil acesso, repleta de termos técnicos e jargões ininteligíveis aos leigos.

A produção de conhecimento e de novas tecnologias interessa a toda a sociedade, não só por ser financiada por ela, mas por ser, ao menos teoricamente, voltada para ela. Nos países subdesenvolvidos, como o Brasil, essa conjetura é ainda mais intensa, já que a posse de tecnologia avançada é frequentemente sinônimo de poder político.

Considerando esse contexto, a divulgação científica adquire um valor especial não só no âmbito financeiro e de disseminação de conhecimento, mas na construção da cidadania (RUÓTOLO, 1998). Avaliar a recepção da informação científica e os efeitos que ela produz no indivíduo são atitudes importantes e necessárias ao estudo da comunicação em geral e da divulgação científica, em particular.

A percepção que a sociedade tem da ciência interessa a cientistas, empresas, políticos e à própria sociedade, na medida em que influencia na tomada de decisões e nas políticas públicas. Assim, é de suma importância que haja estudos sobre a imagem da ciência na sociedade.

...os indicadores de percepção pública sobre C\&T se mostram cada vez mais fundamentais não somente para subsidiar a elaboração e implementação de políticas públicas relacionadas ao tema ou por ela influenciada. Mas, também, para se ter conhecimento de como a imprensa vem "contribuindo" para a construção do imaginário social sobre a C\&T no âmbito da própria atividade científica e seus principais atores, além da compreensão dos conteúdos científicos (FUJIYOSHI, 2004).

Em sua elaboração, o projeto Toque da Ciência se preocupou com os maiores desacertos da divulgação científica identificados nas principais pesquisas de opinião, como a não compreensão de conteúdos e a sensação de distância entre público e cientista. Assim, foram estabelecidos o rádio e a internet, veículos essencialmente democráticos e de fácil acesso, como meios divulgadores do projeto. Os drops, mensagens curtas e de fácil entendimento, são narrados pelo próprio pesquisador, aproximando o cientista 
da sociedade.

Resolvidos dois pontos fundamentais da divulgação científica, é necessária uma reflexão aprofundada sobre a eficácia do projeto e possíveis falhas em seu decurso. Considerando a característica de extensão do Toque da Ciência e seus principais objetivos, os estudos de recepção se apresentam fundamentais para uma avaliação adequada sobre a eficiência dos métodos utilizados e da veracidade dos resultados obtidos.

Um dos aspectos fundamentais para essa compreensão é a análise da linguagem utilizada nos textos do Toque da Ciência, abordada na seção anterior. Buscou-se uma abordagem simplificada, não simplista. O objetivo final de todos os textos elaborados é transmitir com fidelidade informações sobre uma pesquisa, sem que o texto seja prolixo nem carregue um excesso de didatismo. Assim, tem grande valor verificar se tais objetivos têm sido alcançados. Trata-se de um meio de promover mudanças estruturais no projeto nos pontos em que houve equívocos, bem como ressaltar os pontos em que houve sucesso.

As pesquisas de opinião pública, se realizadas regularmente e com metodologia cada vez mais eficaz, podem fornecer dados determinantes para os rumos do projeto. Notando um avanço na compreensão de termos científicos e do contexto histórico em que ocorrem, por exemplo, há a possibilidade de se aprofundar o conteúdo dos textos, que podem futuramente conter mais inovações e menos explicações.

Os estudos sobre recepção permitem avaliar o impacto e a abrangência do projeto devido a essas características, verificando se há uma vantagem significativa em relação a outros meios e se o projeto está cumprindo sua função principal, popularizar a ciência entre o público leigo. Os estudos também tornam possível uma melhor reflexão para a elaboração de "medidores" de recepção, como espaços para opiniões e sugestões dos ouvintes e internautas.

Assim, viabiliza-se não só um valioso painel avaliativo, mas um indicador da importância de se ter um meio diferenciado de divulgação científica, com as características peculiares do projeto. Trata-se de verificar as reais mudanças e vantagens em se promover a aproximação entre ciência e público.

Avaliando não só a recepção do público sobre a ciência, mas a interferência que a mídia e os meios de comunicação provocam na construção do imaginário popular sobre a ciência (cf. CALDAS, 1997), os estudos de recepção podem fornecer dados bastante válidos para o projeto. Tornase possível contornar os erros que a grande mídia comete, intencionalmen- 
te ou não, e propor novos métodos de divulgação científica, que sejam não só mais eficazes, mas que promovam uma mudança de comportamento e atitude na sociedade perante as decisões políticas na área da ciência e tecnologia.

Um estudo adequado sobre a recepção do Toque da Ciência fornecerá uma base sólida para possíveis mudanças no projeto e a possibilidade ser uma experiência única no país na área da divulgação científica, estimulando outros veículos a promover novos métodos e abordagens.

Os estudos de recepção apresentam diversas correntes, muitas delas completamente opostas, mas é certo que o receptor nunca é indiferente ao conteúdo que recebe pelos meios de comunicação. Assim, a análise dos efeitos da comunicação no receptor é imprescindível para uma compreensão satisfatória da comunicação em si e da função do comunicador na sociedade, considerando as conseqüências políticas, econômicas e sociais da difusão de informações (AUGRAS, 1974).

\section{Considerações finais}

Desmistificar a ciência e colocá-la a serviço da coletividade é dever jornalístico e um bem social em si. Para ter qualidade, o jornalismo científico deve demonstrar que fazer C\&T é uma atividade humana, com implicações diretas nas atividades sócio-econômicas e políticas de um país, sendo assim de interesse para toda a sociedade. Enquanto a publicação científica tem circulação restrita e possui uma linguagem repleta de termos técnicos e especificidades, a imprensa pode oferecer o mesmo conteúdo de uma forma mais enxuta e compreensível à maioria dos receptores em potencial. Todavia, o estudante de graduação em Comunicação Social Jornalismo tem pouca oportunidade para exercitar tal prática, pois nas universidades quase não há disciplinas específicas para ela. O Toque da Ciência pretende sanar essa necessidade em sua área geo-institucional - atentando para não se limitar à tradução de termos técnicos, procurando despertar uma consciência crítica sobre CT\&I no público receptor.

A pesquisa em andamento tornará possível monitorar e compreender o processo de produção do produto jornalístico de divulgação científica, um ganho do ponto de vista científico, e também do ponto de vista técnico e cognitivo, pois os mesmos resultados permitirão o aprimoramento dos programas. E um procedimento imprescindível em um projeto de 
natureza também pedagógica, permitindo aos participantes a reflexão sobre suas atividades e a crítica do processo de produção de informação.

\section{Notas}

[1] Um sintoma disso é o fato de o curso de pós-graduação lato sensu em Jornalismo Científico promovida desde 1999 pelo Laboratório de Estudos Avançados em Jornalismo (Labjor) da Universidade Estadual de Campinas (Unicamp) ter suas turmas divididas numa proporção quase idêntica entre pesquisadores e jornalistas.

\section{Referências}

AUGRAS, Monique. Opinião Pública: Teoria e Pesquisa. Petrópolis: Vozes, 1974.

BELDA, Francisco Rolfsen. A informação científica no noticiário: um estudo dos mecanismos de reformulação lingüística no discurso jornalístico de divulgação. Comunicarte, Campinas, v.19 n.25, p. 121-132, 2002.

BURKETT, Warren. Jornalismo Científico. Tradução de Antônio Trânsito. Rio de Janeiro: Forense Universitária, 1990.

BUENO, Wilson. Jornalismo Científico: resgate de uma trajetória. Disponível em: <http://editora.metodista.br/COM30/cap 10.pdf $\rangle$. Acesso em Março de 2006.

CALDAS, Graça. O papel das assessorias de comunicação na divulgação da ciência: a experiência da Unicamp. Comunicarte, Campinas, v.15 n.21, p. 67-79, 1997.

DEL BIANCO, Nélia R. O som da notícia nas teias da rede. In: CONGRESSO BRASILEIRO DE CIÊNCIAS DA COMUNICAÇÃO, 24., 2001, Campo Grande. Anais. São Paulo: Sociedade Brasileira de Estudos Interdisciplinares da Comunicação, 2001

DENCKER, Ada de F. M. e DA VIÁ, Sarah C. Pesquisa empírica em ciências humanas - com ênfase em comunicação. São Paulo: Futura, 2001. 
FAIRCLOGH, Norman. Discurso e mudança social. Brasília: Editora Universidade de Brasília, 1994.

FERRARETTO, Luiz Artur. Rádio - o veículo, a história e a técnica. Porto Alegre: Sagra-Luzzato, 2001.

FOUCAULT, Michel. A Ordem do Discurso. São Paulo: Loyola, 1996.

FUJIYOSHI, Silvia; COSTA, Maria Conceição da. Indicadores de percepção pública da ciência e da tecnologia no Brasil: Estudo comparativo sobre a cobertura da imprensa. 2004. In: 9a Reunião Rede de Popularização da Ciência e Tecnologia para América Latina e o Caribe (RED POP), 2005. Disponível em <www.redpop.org/8reunion/9rrp_ponencias/silviafujiyoshi.doc>. Acesso em 26 fev. 2007.

LAGE, Nilson. A reportagem - teoria e técnica de entrevista e pesquisa jornalistica. Rio de Janeiro: Record, 2001.

. O Jornalismo Científico em Tempos de Confronto. In: CONGRESSO BRASILEIRO DE CIÊNCIAS DA COMUNICAÇÃO, 24., 2003, Belo Horizonte. Anais. São Paulo: Sociedade Brasileira de Estudos Interdisciplinares da Comunicação, 2003

LEITE, Marcelo. Hegemonia e crise da noção de "gene" nos 50 anos do DNA. In: CONGRESSO NACIONAL DE GENÉTICA, 49., 2003, Águas de Lindóia. Anais. Ribeirão Preto: Sociedade Brasileira de Genética, 2003

LÉVY-LEBLOND, Jean-Marc. Cultura científica: impossível e necessária. In: VOGT, Carlos (org.). Cultura cientifica - desafios. São Paulo: Edusp/ Fapesp, 2006. p.28-43.

LÈVY, Pierre. Cibercultura. São Paulo: Ed. 34, 1999. 264p.

LOPES, Maria Immacolata Vassallo de. Pesquisa em Comunicação: formulação de um modelo metodológico. 4. ed. São Paulo: Loyola, 1999.

MEDEIROS, A. L. Desafios e limitações do jornalismo científico na televisão brasileira. In: SOUZA, C. M. (org); FERREIRA, J. R. (org.); BORTOLIERO, S. (org.). Jornalismo Cientifico e Educação para as Ciências. Tau- 
baté: Cabral, 2006.

NARDI, Fabiele Stockmans De. Entre a estrutura e o acontecimento: Uma releitura de Pêcheux e Foucault em busca do sistema. Disponível em <http:// www.discurso.ufrgs.br/article.php3? id_article=13>. Acesso em: 14 fev. 2007.

OLIVEIRA, Fabíola. Jornalismo Científico. São Paulo: Contexto, 2002.

ORLANDI, Eni Puccinelli. Análise de discurso: princípios e procedimentos. 3. ed. Campinas: Pontes, 2001.

PECHEUX, Michel. O discurso. 4. ed. Campinas: Pontes, 2006. Semântica e discurso. 2. ed. Campinas: Editora da Unicamp, 1995.

PINSKY, Jaime e PINSKY, Carla Bassanezi (Org.). História da Cidadania. São Paulo: Contexto, 2003.

PINTO, Milton José. Comunicação e discurso: Introdução à Análise de discursos. São Paulo: Hacker Editores, 1999.

RUOTÓLO, Antônio Carlos. Audiência e recep̧̧ão: perspectivas. Comunicação e Sociedade. São Bernardo do Campo-SP: Instituto Metodista de Ensino Superior, no 30,1998. Texto disponível em: http://editora.metodista.br/COM30/cap_07.pdf. Acesso em 28 fev. 2007.

SABBATINI, Marcelo. O astronauta brasileiro e o "Regresso das Estrelas": mito e política científica na análise de conteúdo da cobertura da missão Centenário da Agência Espacial Brasileira. In: CONGRESSO BRASILEIRO DE CIÊNCIAS DA COMUNICAÇÃO, 29., 2006, Brasília. Anais. São Paulo: Sociedade Brasileira de Estudos Interdisciplinares da Comunicação, 2006

SANTAELLA, Lúcia. Comunicação e Pesquisa. São Paulo: Hacker Editores, 2001.

SANTOS, Cristina Mascarenhas; BORTOLIERO, Simone. Observando os conflitos: a história da terapia com células-tronco para tratamento da doença de Chagas e a veiculação de notícias na Bahia In: CONGRESSO 
BRASILEIRO DE CIÊNCIAS DA COMUNICAÇÃO, 29., 2006, Brasília. Anais. São Paulo: Sociedade Brasileira de Estudos Interdisciplinares da Comunicação, 2006

SAVIANI REY, Luiz Roberto. Jornal Impresso e Pós-Modernidade: Projeto Ruth Clark e a espetacularização da notícia. Revista de estudos de Jornalismo, Campinas, v.3/4, n. 2, p.31-40, jul. 2000 - jun. 2001.

SILVEIRA, Ada Cristina Machado da Silveira (org.). Divulgação científca e tecnologias de informação e comunicação. Santa Maria: FACOS-UFSM, 2003.

TRIGUEIRO, Osvaldo. O estudo científico da comunicação: avanços teóricos e metodológicos ensejados pela escola latino-americana. PCLA, v. 2, n. 2, jan-mar. 2001. Disponível em < http://www2.metodista.br/unesco/ PCLA/revista6/artigo\%206-3.htm>. Acesso em 06 mar 2007

VOGT, Carlos (org.). Cultura cientifica - desafios. São Paulo: Edusp/Fapesp, 2006.

VOGT, Carlos; POLINO, Carmelo. Percep̧̧ão Pública da Ciência: resultados da pesquisa na Argentina, Brasil, Espanha e Uruguai. Campinas/São Paulo: Editora da Unicamp/Fapesp, 2003. 
*Juliano Maurício de Carvalho

Doutor em Comunicação Social pela Umesp.

Professor do Programa de Pós-Graduação em

Comunicação Midiática (Unesp/Bauru);

E-mail: juliano@faac.unesp.br

** Aline Emi Naoe

Graduada em Jornalismo (Unesp/Bauru). Membro do Laboratório de Estudos em Comunicação, Tecnologia e Educação Cidadã - LECOTEC;

E-mail: alinenaoe@faac.unesp.br

*** Érica Masiero Nering

Graduanda em Jornalismo (Unesp/Bauru). Membro do Laboratório de Estudos em Comunicação, Tecnologia e Educação Cidadã - LECOTEC;

E-mail: ericanering@faac.unesp.br

**** Fábio de Lima Alvarez

Graduando em Jornalismo (Unesp/Bauru). Membro do Laboratório de Estudos em Comunicação, Tecnologia e Educação Cidadã - LECOTEC;

E-mail: fabio.alvarez@faac.unesp.br

******* João Guilherme D'Arcadia

Mestrando em Jornalismo (Unesp/Bauru). Membro do Laboratório de Estudos em Comunicação, Tecnologia e Educação Cidadã - LECOTEC;

E-mail: joaodarcadia@faac.unesp.br

******* Mateus Yuri Passos

Mestre em Ciência, Tecnologia e Sociedade na Ufscar. Membro do Laboratório de Estudos em Comunicação, Tecnologia e Educação Cidadã LECOTEC (Unesp).

E-mail:mpassos@faac.unesp.br 